\title{
Efeito do tratamento térmico de alívio de tensão e do preaquecimento na microestrutura e microdureza da interface entre depósitos de inconel 625 e aços AISI $8630 \mathrm{M}$ e AISI 4130
}

\author{
Effect of stress relief heat treatment and preheating on \\ the microstructure and microhardness of the interface \\ between Inconel 625 deposit and AISI 8630M and AISI 4130 steels
}

\author{
Valmir Rodrigues Batista ${ }^{1}$, Endira Maria Araújo Pereira ${ }^{2}$, \\ Ramon da Cunha Fonseca Fraga ${ }^{2}$, Theophilo Moura Maciel ${ }^{2}$
}

\footnotetext{
${ }^{1}$ Laboratório de Soldagem-LABSOL, UAEMa/CCT/UFCG, CEP. 58429-900, Campina Grande, Paraíba, Brasil,

${ }^{2}$ Laboratório de Soldagem - LABSOL, UAEM/CCT/UFCG, CEP. 58429-900, Campina Grande, Paraíba, Brasil, e-mail: valmir5@yahoo.com.br, endiraaraujo@gmail.com, ramonffraga@gmail.com, theo@ dem.ufcg.edu.br
}

\begin{abstract}
RESUMO
O objetivo deste trabalho foi avaliar o efeito da aplicação de tratamento térmico de alívio de tensão (TTAT) e das temperaturas de preaquecimento e de interpasse sobre a microestrutura, presença de zonas parcialmente diluídas (ZPD), a microdureza e o gradiente de composição ao longo da interface de depósitos da liga AWS E NiCrMo 3 sobre os aços AISI 8630M e AISI 4130 aplicados por dois processos de soldagem (GMAW e PTA-P). Para isto foram executadas camadas sobrepostas de cordões de solda, utilizando diferentes temperaturas de preaquecimento e de interpasse. Os processos de soldagem utilizados foram os processos MIG e Plasma Pó (PTA-P). Em seguida, as interfaces dos depósitos foram submetidas às análises de composição química via EDS, às análises metalográficas por via ótica e eletrônica e a ensaios de microdureza $\mathrm{O}$ aumento da temperatura de preaquecimento e de interpasse resultou em maior refino dos grãos da zona termicamente afetada dos aços (ZTA) do primeiro passe, em um aumento da microdureza na ZTA, e em uma maior migração de Fe do substrato para a camada aplicada. Foi verificada uma menor diversidade e frequência de incidência de ZPD nos depósitos executados pelo processo Plasma Pó, enquanto que nos depósitos executados com o processo MIG foram encontradas ZPD do tipo descontínua, com diferentes morfologias. A aplicação do TTAT resultou em redução significativa nos valores de microdureza em todos os casos.
\end{abstract}

Palavras-chave: Microestrutura, Zona parcialmente diluída, Processo PTA-P, Inconel 625, Amanteigamento.

\section{ABSTRACT}

The objective of this study was to evaluate the effect of the preheating and interpass temperature, as well as to evaluate the effect of the application of stress relief heat treatment on the microstructure, microhardness and composition gradient along the interface of AWS E NiCrMo3 alloy on AISI8630M and AISI4130 quenched and tempered steel, applied by two welding process. For this superimposed weld beads using different preheat and interpass were applied using MIG and Plasma Transfered Arc - Powder (PTA-P) welding process. The interfaces deposits were subjected to analysis of chemical composition by EDS, to metallographic examination by optical and electronic microscopy and to microhardness tests. The increase in preheat and interpass temperatures resulted in greater grain refinement of the first pass, increase of heat affected zone microhardness and in a greater Fe migration from the substrate to the applied layer. A minor frequency diversity and a lower incidence of partially diluted zones (PDZ) was observed in deposits performed by PTA-P process, where as the deposits performed with MIG process discontinuous PDZ type 
with different morphologies were identified. The use of stress relief heat treatment resulted in a significant reduction in microhardness values in all cases.

Key-words: Microstructure, Partially-mixed zone, PTA-P welding process, Inconel 625, Buttering.

\section{INTRODUÇÃO}

Aços de alta resistência temperados e revenidos, como os aços AISI 8630 e 4130, são comumente utilizados na confecção de válvulas submarinas, os quais devem ser soldados a tubulações para condução do petróleo. $\mathrm{Na}$ tentativa de impedir a corrosão destes equipamentos em ambientes marinhos utilizam-se, entre algumas técnicas, a proteção catódica. Entretanto, esta técnica gera hidrogênio livre que pode provocar a fragilização em regiões susceptíveis a este problema, como é o caso da zona termicamente afetada das juntas soldadas dos aços citados anteriormente $[1,2]$.

Para reduzir o risco de trincas na junta, cordões de solda denominados de amanteigamento são aplicados no aço temperado antes da união definitiva. $\mathrm{O}$ material utilizado neste amanteigamento deve ser uma liga tenaz, isenta da formação de microestruturas frágeis e capaz de absorver as restrições às dilatações da junta e de eventuais diferenças entre os coeficientes de expansão térmica entre os materiais dissimilares a serem soldados. As ligas mais utilizadas para este fim são ligas de Ni ou de aço de baixo carbono [1, 3-7]. Em seguida, a parte "amanteigada" é submetida a tratamentos térmicos pós soldagem (TTPS) para reduzir o nível de tensões, evitando a aplicação deste tratamento após a soldagem de união. Entretanto, o ciclo térmico do TTPS deve ser bem planejado para evitar uma elevada difusividade dos elementos durante o tratamento, o que pode gerar regiões descarbonetadas e comprometer a formação de carbonetos estáveis [9]. Além disso, nos procedimentos padrões da indústria para TTPS de aços AISI8630, a difusão de carbono pode resultar na formação prejudicial de carboneto $\mathrm{M}_{7} \mathrm{C}_{3}$, dentro da zona solidificada planar (zona $\phi$ ) [7]. Dai e Loppold, em um estudo sobre resistência a fragilização por hidrogênio, mostraram, através de um parâmetro que leva em consideração duas variáveis, a temperatura e o tempo do tratamento térmico, que existem combinações mais favoráveis que outras entre essas variáveis [8]. Uma alternativa para evitar a aplicação do TTPS é a utilização de energias de soldagem mais elevadas na aplicação da segunda camada de amanteigamento, com relações de energia entre as camadas de $1: 1$ a 2:1, proporcionando o refino da ZTA do primeiro passe, melhorando a tenacidade da região $[5,10,11]$. No caso deste estudo, foi utilizada a relação 1:1.

Entretanto, na interface destes amanteigamentos com o metal de base (MB), devido ao elevado gradiente de composição química, podem ser formadas zonas parcialmente diluídas (ZPD), microfases e carbonetos de elevada dureza que podem comprometer a tenacidade e originar trincas devido à presença do hidrogênio nestas regiões, especialmente nas ZPD descontínuas denominadas de "swirls" ou "redemoinhos", que possuem microestrutura martensítica, de baixa tenacidade, assim como os carbonetos. Beltrão, Dodge et al. e Batista mostram mais detalhes e discutem algumas dessas constatações. [6, 7, 12]

Os fenômenos metalúrgicos indesejáveis, citados anteriormente, podem ser minimizados através da utilização de parâmetros e processos de soldagem adequados. Um parâmetro de soldagem, que pode influenciar significativamente na ocorrência desses fenômenos, são as temperaturas de preaquecimento e de interpasse dos passes do amanteigamento, já que esses parâmetros causam mudanças nos ciclos de aquecimento e resfriamento da solda, impactando no tamanho dos grãos e processos de difusão atômica. Outro parâmetro é aplicação de TTAT, mas a temperatura e o tempo de aquecimento devem ser bem estudados, pois a formação de carbonetos duros pode acontecer com o processo de envelhecimento, comprometendo a resistência ao trincamento [7, 8, 12]. Algumas pesquisas apresentam o uso do processo GMAW para aplicação de revestimentos e amanteigamentos $[6,7,12]$. No entanto, o processo Plasma Pó (PTA-P) vem ganhando destaque em aplicação de revestimentos devido à excelente qualidade das soldas e aos baixos níveis de diluição alcançados. [13, 14]

O processo PTA-P utiliza um eletrodo de tungstênio não consumível, situado no interior da tocha, um bico constritor, que restringe a área de atuação do plasma, um sistema de refrigerado com água, gás de proteção para a poça fundida e gás de plasma. Até aqui o PTA-P é semelhante ao processo PAW (Plasma Arc Weld). A diferença entre eles está na natureza do metal de adição (arame e pó no PAW e PTA-P, respectivamente). Na soldagem PTA-P, o metal de adição é transportado até o arco elétrico através da vazão de um gás chamado de gás de arraste. [12]

Sendo assim, este trabalho visou avaliar o efeito da aplicação de TTAT, das temperaturas de preaquecimento e de interpasse e da utilização do processo PTA-P em comparação a outro processo 
amplamente conhecido e utilizado, o MIG, sobre o gradiente de composição química, a proporção de microfases, principalmente as zonas parcialmente diluídas (ZPD) e o perfil de microdureza ao longo da interface entre cordões de solda de liga de Ni depositados sobre aços AISI 8630M e AISI 4130 utilizados na fabricação de válvulas submarinas.

\section{MATERIAIS E MÉTODOS}

Como substrato (metal de base), foram utilizadas chapas dos aços AISI 8630M e AISI 4130, ambos temperados e revenidos, com dimensões de 250 × 87 × $32 \mathrm{~mm}$, apresentando ambos, microestrutura de martensita revenida. O certificado de qualidade do fabricante indica durezas de 248 a $260 \mathrm{HV}$ para o AISI $8630 \mathrm{M}$ e 238 a 260HV para AISI 4130. Como material de adição, foi utilizada a liga AWS ER NiCrMo-3 (Inconel-625) na forma de arame com 1,2 mm de diâmetro para o processo MIG e na forma de pó atomizado, apresentando faixa de granulométrica de 60 a $63 \mu \mathrm{m}$, para o processo PTA-P. Nas Tabelas 1e 2 estão apresentadas as composições químicas da liga Inconel - 625 e dos metais de base respectivamente

Tabela 1: Composição química nominal da liga Inconel-625 em pó e arame.

\begin{tabular}{c|c|c|c|c|c|c|c|c|c|c|c|c|c}
\hline \multicolumn{10}{c}{ COMPOSIÇÃO QUÍ́ICA (\%) } \\
\hline $\begin{array}{c}\text { ELEMENTO } \\
\text { QUímICO }\end{array}$ & $\mathrm{Cr}$ & $\mathrm{Fe}$ & $\mathrm{Mo}$ & $\mathrm{Nb}+\mathrm{Ta}$ & $\mathrm{C}$ & $\mathrm{Mn}$ & $\mathrm{Si}$ & $\mathrm{P}$ & $\mathrm{S}$ & $\mathrm{Al}$ & $\mathrm{Ti}$ & $\mathrm{Co}$ & $\mathrm{Ni}$ \\
\hline ARAME & 20,6 & 0,22 & 8,14 & 3,49 & 0,024 & 0,06 & 0,06 & 0,005 & 0,001 & 0,32 & 0,34 & 0,02 & 66,66 \\
\hline PÓ & 21 & 3 & 9,2 & 3,5 & 0,05 & - & - & - & - & - & - & - & bal. \\
\hline
\end{tabular}

Fonte: Certificado de qualidade do fabricante

Tabela 2: Composição química (\% em peso) dos metais de base

\begin{tabular}{l|l|l|l|l|l|l|l|l|l|l}
\hline \multirow{2}{*}{ METAL DE BASE } & \multicolumn{10}{c}{ ELEMENTOS } \\
\cline { 2 - 12 } & $\mathrm{C}$ & $\mathrm{Si}$ & $\mathrm{Mn}$ & $\mathrm{P}$ & $\mathrm{S}$ & $\mathrm{Cr}$ & $\mathrm{Mo}$ & $\mathrm{Ni}$ & $\mathrm{Al}$ & $\mathrm{Cu}$ \\
\hline AISI $8630 \mathrm{M}$ & 0,32 & 0,30 & 0,86 & 0,006 & 0,011 & 0,93 & 0,38 & 0,81 & 0,02 & 0,06 \\
\hline AISI 4130 & 0,29 & 0,27 & 0,58 & 0,007 & 0,005 & 0,91 & 0,18 & 0,05 & 0,000 & 0,10 \\
\hline
\end{tabular}

Fonte: Certificado de qualidade do fabricante

O gás de plasma e de arraste no processo PTA-P e de proteção para ambos os processos foi o Argônio puro (Argônio comercial).

Antes da aplicação do amanteigamento as amostras foram aquecidas, com uma chama oxiacetilênica neutra, nas temperaturas indicadas na Tabela 3, que apresenta também as temperaturas de interpasse para cada caso. As temperaturas de preaquecimento variaram de 200 a $280{ }^{\circ} \mathrm{C}$ e foram monitoradas utilizando-se um pirômetro digital. Essas faixas de temperatura de preaquecimento e interpasse foram escolhidas com base em recomendações do Cenpes/Petrobras e da literatura para os respectivos aços [15, 17].

Tabela 3: Temperaturas de preaquecimento e de interpasse.

\begin{tabular}{l|l|l|l|l}
\hline AMOSTRA & METAL DE BASE & PROCESSO & T. PREAQUECIMENTO $\left({ }^{\circ} \mathbf{C}\right)$ & T. INTERPASSE $\left({ }^{\circ} \mathbf{C}\right)$ \\
\hline A1-86P & AISI 8630M & PTA-P & 200 & 240 \\
\hline A2-86P & AISI 8630M & PTA-P & 240 & 280 \\
\hline B1-41P & AISI 4130 & PTA-P & 200 & 240 \\
\hline B2-41P & AISI 4130 & PTA-P & 240 & 280 \\
\hline B3-41P & AISI 4130 & PTA-P & 280 & 370 \\
\hline C1-86M & AISI 8630M & MIG & 200 & 240 \\
\hline C2-86M & AISI 8630M & MIG & 240 & 280 \\
\hline C3-86M & AISI 8630M & MIG & 280 & 370 \\
\hline D1-41M & AISI 4130 & MIG & 200 & 240 \\
\hline
\end{tabular}

O equipamento de soldagem utilizado para todos os amanteigamentos, em ambos os processos, foi a fonte do modelo multiprocesso DIGI Plus A7 800, fabricada pela IMC Soldagem, com capacidade de corrente máxima de 800 A. O alimentador de pó foi do tipo tambor dosador. Vale salientar que o modelo da tocha PTA-P tem quatro canais de alimentação do pó em torno do orifício constritor com ângulo de convergência de $60^{\circ}$.

Para a determinação de parâmetros satisfatórios para a deposição dos cordões de solda dos 
amanteigamentos, foram observados valores já estudados por outros autores [13, 14, 17]. Esses parâmetros foram testados e sofreram pequenos ajustes para resultar em um perfil geométrico adequado, com uniformidade na largura $(\mathrm{L})$ e altura $(\mathrm{R})$, valor relativamente baixo da relação R/L e baixa diluição, determinada através da Equação 1 . O valor da sobreposição entre os cordões utilizada foi de $50 \%$ de $\mathrm{L}$, conforme ilustrado na Figura 1. Como foram depositadas várias camadas, foi necessário calcular a diluição global após a primeira camada e antes da deposição das camadas seguintes.
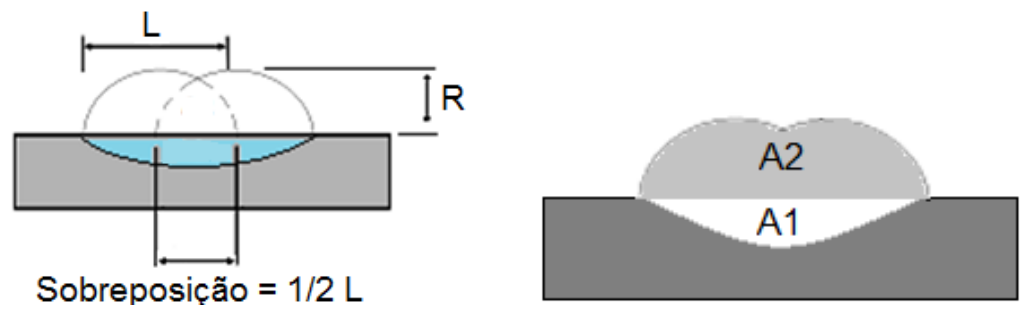

Figura 1: Ilustração das dimensões dos cordões e da sobreposição dos cordões

$$
D(\%)=\frac{A 1}{A 1+A 2}(100)
$$

Os parâmetros de soldagem utilizados pelos processos PTA-P e MIG estão apresentados nas Tabelas 4 e 5 respectivamente.

Tabela 4: Parâmetros de soldagem utilizando o processo PTA-P.

\begin{tabular}{l|l|l|l|l}
\hline PARÂMETRO & VALOR & & PARÂMETRO & VALOR \\
\hline Corrente de soldagem $(\mathrm{A})$ & 195 & & Vazão do Gás de Proteção $(\mathrm{L} / \mathrm{min})$ & 10 \\
\hline Tensão de arco resultante $(\mathrm{V})$ & 29 & & Distância bico - peça, DBP $(\mathrm{mm})$ & 20 \\
\hline Velocidade de soldagem $(\mathrm{cm} / \mathrm{min})$ & 14 & & Recuo de eletrodo $(\mathrm{mm})$ & 1,5 \\
\hline Taxa de alimentação do pó $(\mathrm{g} / \mathrm{min})$ & 34 & & Diâmetro do Bico $(\mathrm{mm})$ & 3,2 \\
\hline Vazão do Gás de Arraste $(\mathrm{L} / \mathrm{min})$ & 3 & & Ângulo da Tocha com a vertical $\left({ }^{\circ}\right)$ & 0 \\
\hline Vazão do Gás de Plasma (L/min) & 2,2 & & Ângulo de alimentação do pó $\left({ }^{\circ}\right)$ & 60 \\
\hline
\end{tabular}

Tabela 5: Parâmetros de soldagem utilizando o processo MIG.

\begin{tabular}{l|c}
\hline PARÂMETRO & VALOR \\
\hline Tensão de arco $(\mathrm{V})$ & 30 \\
\hline Velocidade de alimentação do arame $(\mathrm{m} / \mathrm{min})$ & 8,4 \\
\hline Corrente média de soldagem $(\mathrm{A})$ & 260 \\
\hline Velocidade de soldagem $(\mathrm{cm} / \mathrm{min})$ & 30 \\
\hline Vazão do Gás de Proteção $(\mathrm{L} / \mathrm{min})$ & 17 \\
\hline Distância bico - peça, DBP $(\mathrm{mm})$ & 18 \\
\hline Ângulo da Tocha com a vertical $\left(^{\circ}\right)$ & 0 \\
\hline
\end{tabular}

Foi estipulada uma altura mínima do amanteigamento de $9 \mathrm{~mm}$ depois de retificado, aproximadamente o valor utilizado por BRITO [10]. Para isso, foi preciso aplicar 2 camadas de amanteigamento na peça, pelo processo PTA-P, o que resultou em amanteigamentos com alturas variando de 10 a $12 \mathrm{~mm}$. Para atingir esta mesma altura de amanteigamento utilizando o processo MIG foi necessário o depósito de 3 camadas, ao invés das duas utilizadas no processo PTA-P.

Para a análise da microestrutura foi utilizado um microscópio óptico acoplado a um computador e um software analisador de imagens. As amostras cortadas foram embutidas, lixadas em lixas de 100 a 1200 mesh, depois polidas com aluminas de granulometria $1 \mu \mathrm{m}, 0,3 \mu \mathrm{m}$ e $0,05 \mu \mathrm{m}$ respectivamente. $\mathrm{O}$ ataque metalográfico foi com o reagente químico Nital, a $1 \%$, sendo o suficiente para os objetivos da pesquisa que inclui observar as estruturas ao redor da linha de fusão, como a zona termicamente afetada do metal de base e as zonas parcialmente diluídas. Além da Microscopia Ótica, as amostras foram analisadas por Microscopia Eletrônica de Varredura (MEV) para identificar com melhor nitidez as diferentes microrregiões, 
principalmente as zonas parcialmente diluídas (ZPD) e por EDS para avaliar o gradiente de composição química ao longo da interface.

Foram realizados ensaios de microdureza, tanto no sentido horizontal ao longo de toda extensão da interface, como no sentido vertical, ou seja, da região do metal de base - não afetado pelo ciclo térmico de soldagem - até próximo à superfície do revestimento. Os resultados de microdureza foram correlacionados com o gradiente de composição química e a proporção das microfases, ZPDs e carbonetos, mostram a influência da temperatura de preaquecimento e do uso de TTAT. A Figura 2 ilustra os locais onde foram medidos os valores de microdureza. A carga aplicada para realização do ensaio de microdureza ao longo dos perfis verticais foi de 100 gramas força (gf) durante 15 segundos, com impressões separadas por $500 \mu \mathrm{m}$ de distância. Para a região ao longo da linha de fusão (LF), que se tornou objeto de estudo da pesquisa a carga foi de 25 gramas forças (gf) durante 15 segundos.

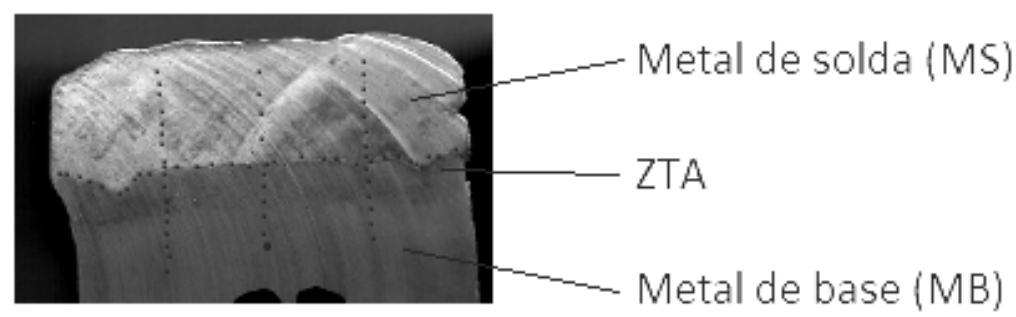

Figura 2: Localização das impressões de microdureza nas chapas amanteigadas.

Após a aplicação dos amanteigamentos os corpos de prova foram submetidos a um tratamento térmico para alívio de tensão, TTAT, cujos parâmetros foram estabelecidos de acordo com a norma NACE MR0175/ISO 15156-2:2003 [18]. O aquecimento foi realizado até $676^{\circ} \mathrm{C}$, mantendo essa temperatura por um período de 2 horas. A taxa de aquecimento foi de $12^{\circ} \mathrm{C} / \mathrm{min}$. $\mathrm{O}$ resfriamento ocorreu dentro do próprio forno, resultando em uma taxa de resfriamento de aproximadamente $6,4^{\circ} \mathrm{C} / \mathrm{min}$.

\section{RESULTADOS}

Os cordões isolados obtidos pelo processo PTA-P apresentaram as seguintes dimensões médias: 12,3 mm de largura (L) e 3,9 mm de altura (R). Porém, com a sobreposição de 50\% entre os cordões, a primeira camada ficou em média com 5,4 mm de altura. Isso garantiu que, com duas camadas, o amanteigamento atingisse no mínimo $10 \mathrm{~mm}$ de altura. Os cordões de solda obtidos pelo processo MIG apresentaram as seguintes dimensões médias: $11,5 \mathrm{~mm}$ de largura (L) e 3,4 mm de altura (R). Com a sobreposição de $50 \%$ entre os cordões, a primeira camada apresentou de $4 \mathrm{~mm}$ de altura, necessitando de três camada para atingir valores mínimos de $10 \mathrm{~mm}$, sendo submetida portanto a um ciclo térmico de sobreposição a mais que o PTA-P. Nesse caso, espera-se que este terceiro ciclo não tenha nenhuma influência sobre a ZTA do metal de base devido a distância relativamente grande. No entanto, espera-se que com uma sobreposição lateral de 50\%, em qualquer que seja o processo, a diluição seja menor do que se fosse utilizada uma sobreposição menor que $50 \%$, pois metade do arco se concentra em cima do cordão anterior. Além disso, o aporte térmico em cima do cordão anterior tende a refinar a ZTA desse ultimo.

A Tabela 6 mostra os resultados das geometrias dos cordões depositados pelos dois processos, onde $\mathrm{L}_{0}$ é a altura da chapa sem amanteigamento, $\mathrm{L}_{\text {mín }}$ é a altura mínima da chapa com amanteigamento, $\mathrm{L}_{\text {máx }}$ é a altura máxima da chapa amanteigada, $\mathrm{R}$ é a altura da camada do amanteigamento sem retificação e $\mathrm{D}$ é o valor da diluição global dos amanteigamentos. Nota-se que todos os amanteigamentos ficaram com no mínimo $10 \mathrm{~mm}$ de altura. Os valores mínimos correspondem às bordas dos amanteigamentos, onde foram aplicados o primeiro e ultimo cordão de cada camada, onde o metal escorre para a lateral (Figura 2) e os valores máximos correspondem às regiões mais próximas dos cordões centrais do amanteigamento.

Tabela 6: Dimensões dos cordões de solda dos amanteigamentos

\begin{tabular}{l|l|l|l|l|l}
\hline CORPO DE PROVA & $\mathbf{L}_{\mathbf{0}}(\mathbf{m m})$ & $\mathbf{L}_{\min }(\mathbf{m m})$ & $\mathbf{L}_{\operatorname{máx}}(\mathbf{m m})$ & $\mathbf{R}(\mathbf{m m})$ & $\mathbf{D}(\%)$ \\
\hline A1-86P & 87,0 & 98,5 & 101,7 & $11,5-14,7$ & 14,3 \\
\hline A2-86P & 89,0 & 99,0 & 101,0 & $10,0-12,0$ & 16,3 \\
\hline B1-41P & 87,5 & 97,5 & 99,4 & $10,0-11,9$ & 9,9 \\
\hline B2-41P & 87,3 & 97,7 & 100,0 & $10,4-12,7$ & 10,2 \\
\hline
\end{tabular}




\begin{tabular}{l|l|l|l|l|l}
\hline B3-41P & 87,5 & 97,5 & 100,2 & $10,0-12,7$ & 10,3 \\
\hline C1-86M & 87,1 & 97,3 & 101,0 & $10,2-13,9$ & 18,4 \\
\hline C2-86M & 87,2 & 97,2 & 101,0 & $10,0-13,8$ & 24,3 \\
\hline C3-86M & 87,3 & 97,5 & 99,2 & $10,2-11,9$ & 29,6 \\
\hline D1-41M & 87,5 & 98,0 & 102,0 & $10,5-14,5$ & 22,8 \\
\hline
\end{tabular}

Da Figura 3 a 5 podem ser observadas as seções transversais dos amanteigamentos das chapas pelos processos PTA-P e MIG. Os valores evidenciados correspondem à penetração em "mm" do metal de solda (MS) no metal de base (MB). A linha horizontal preta corresponde ao limite da chapa antes do amanteigamento.

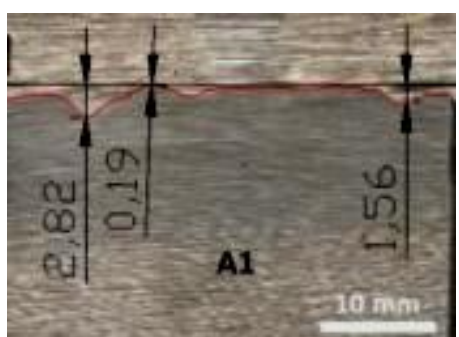

(a)

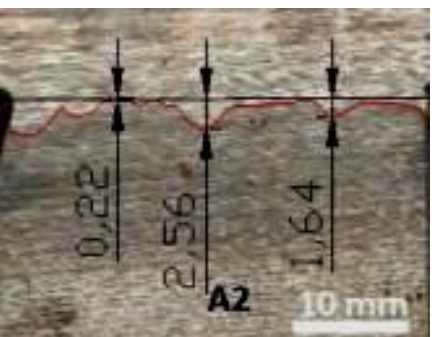

(b)

Figura 3: Seção transversal dos amanteigamentos das chapas AISI 8630M com PTA-P. a) Amostra A1-86P. b) Amostra A2-86P.

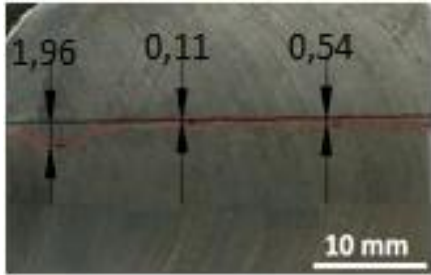

(a)

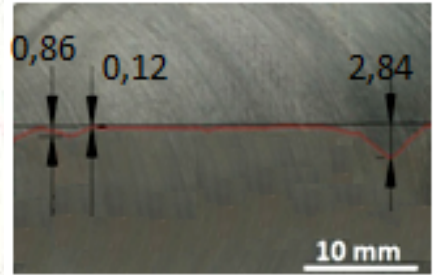

(b)

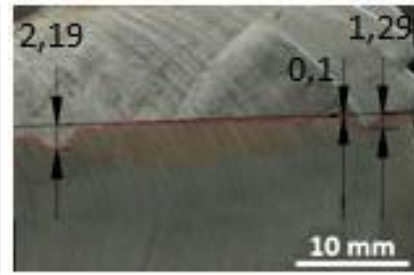

(c)

Figura 4: Seção transversal dos amanteigamentos das chapas de AISI 4130 com PTA-P. a) Amostra B1-41P. b) Amostra B2-41P. c) Amostra B3-41P.

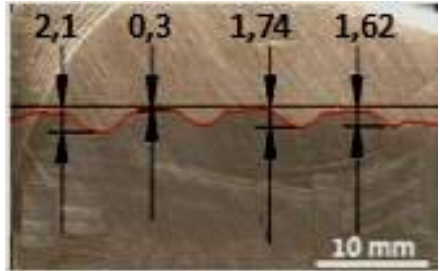

(a)

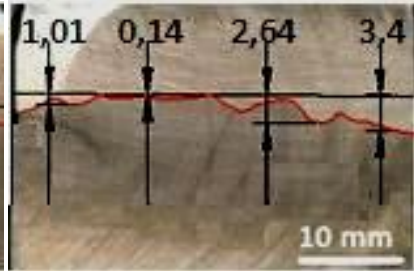

(b)

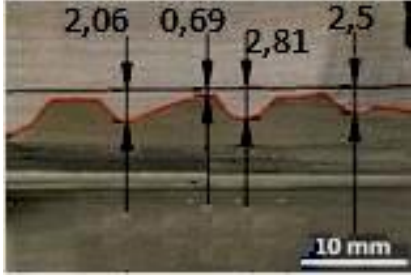

(c)

Figura 5: Seção transversal dos amanteigamentos das chapas AISI 8630M com MIG. a) Amostra C1-86M. b) Amostra C2-86M. c) Amostra C3-86M.

As Figuras 6 e 7 apresentam as interfaces dos amanteigamento com o aço AISI 8630M utilizando os processos PTA-P e MIG, onde, nos amanteigamentos realizados pelo MIG, são observadas estruturas denominadas "dedo", caracterizadas por uma penetração do metal de solda (MS) no metal de base (MB) e serão detalhadas e discutidas posteriormente. 


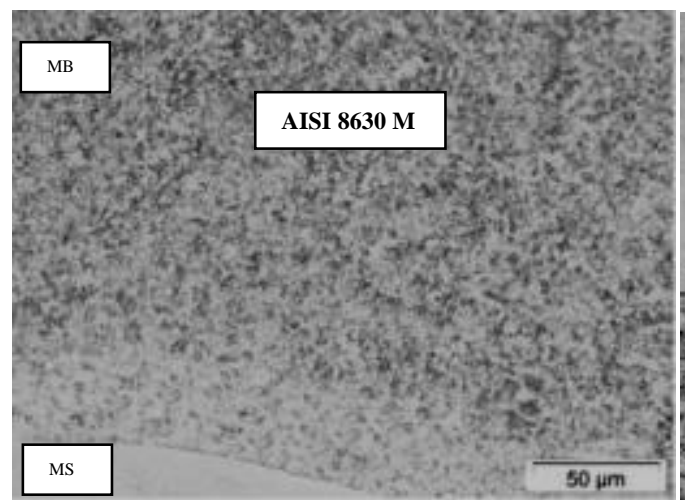

(a)

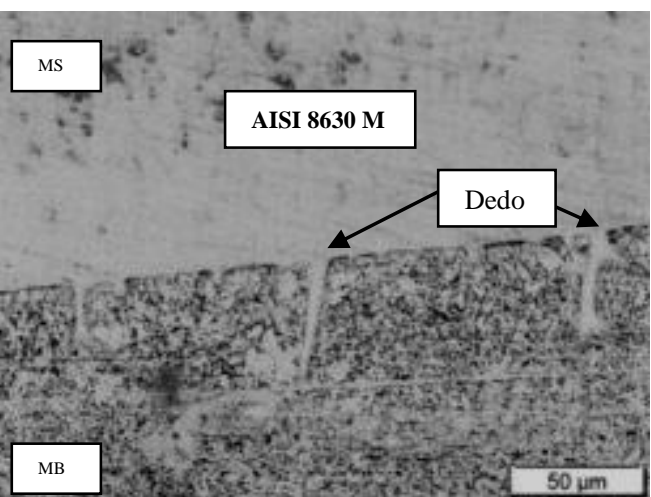

(b)

Figura 6: Microestrutura da interface do amanteigamento com o aço AISI 8630M utilizando o processo PTA-P (a) e o processo MIG (b).

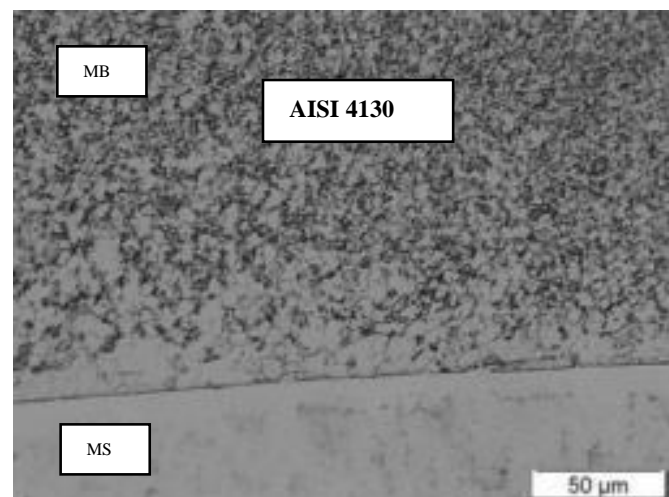

(a)

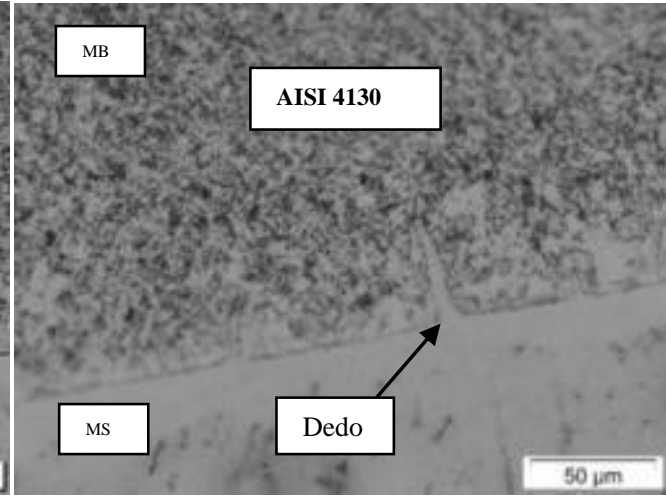

(b)

Figura 7: Microestrutura da interface do amanteigamento com o aço AISI 4130 utilizando o processo PTA-P (a) e o processo MIG (b).

Além dessas penetrações, foi possível identificar a ocorrência de zonas parcialmente diluídas (ZPD) na interface entre a liga de Ni e o aço carbono. Essas ZPDs são ilustradas na Figura 8. De acordo com as definições de Beaugrand, na Figura 8 tem-se entre o metal de base e o amanteigamento [1] :

1) Zona $\Delta$ - zona descarbonetada dentro da região de grãos grosseiros da ZTA, podendo apresentar estruturas chamadas de "dedos", como visto nas Figuras 6 e 7.

2) Zona M - Região de microestrutura martensítica (TCC), aparecendo principalmente nas regiões inter-passes onde podem ser observadas estruturas denominadas "Swirl" ou redemoinhos (Figura 9).

3) Zona $\phi$ - Zona de elevada dureza. Solução sólida austenítica da ZPD supersaturada de carbono , solidificada de forma planar.

4) Zona $\pi$ - Região que contém grande número de partículas interdendríticas de elevado número atômico (zona П). Esta zona exibe uma matriz austenítica CFC; 


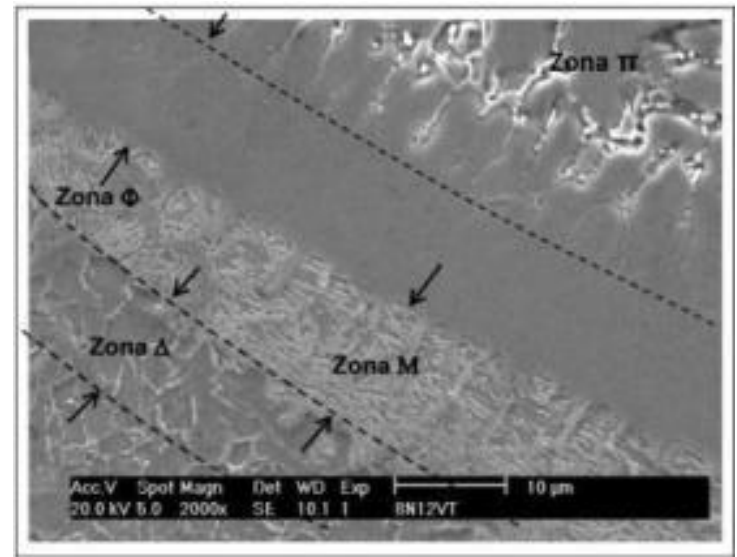

Figura 8: Ilustração dos tipos de ZPD na interface entre o aço AISI 8630M e a Liga de Ni, Inconel 625 [19].

A Figura 9 apresenta alguns tipos de ZPD encontradas e a Figura 10 a presença da zona M, descontínua, em uma amostra amanteigada com o processo MIG, juntamente com as zonas $\Phi$ e $\Delta$. A região chamada de península (devido a sua semelhança com o acidente geográfico com esse nome) também é chamada de "swirl" por Dai e Lippold e por Dodge [7, 8].

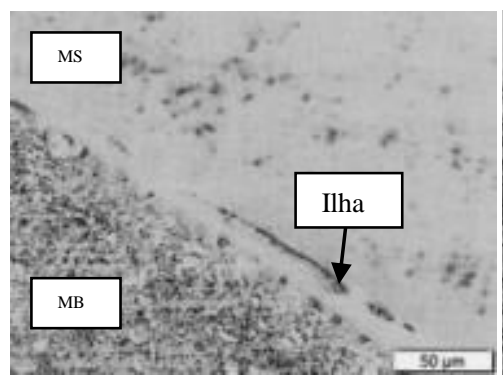

(a)

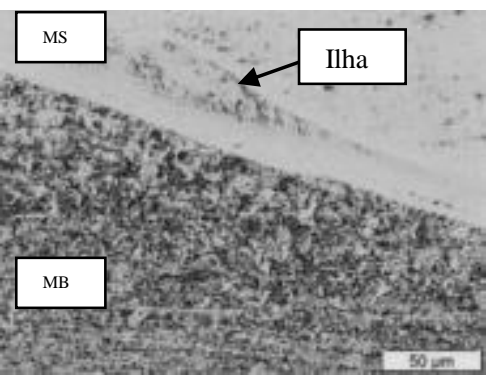

(b)

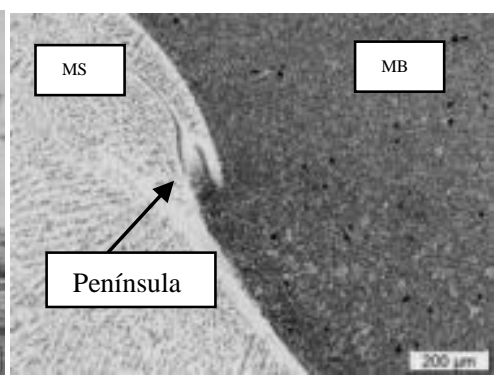

(c)

Figura 9: ZPDs descontínuas identificadas nas interfaces dos amanteigamentos executados com o processo MIG: ilhas de zona M (a), (b), península (c).

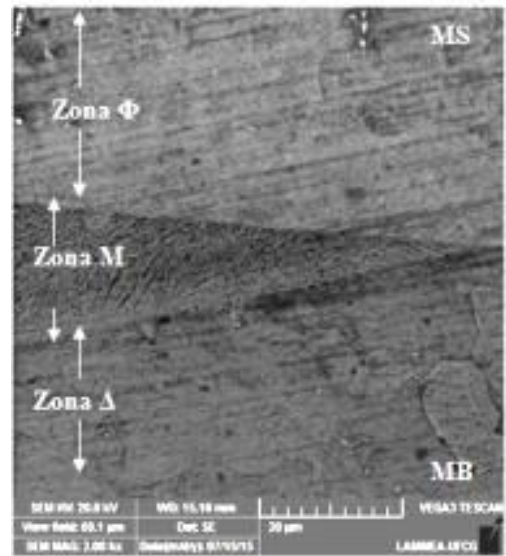

Figura 10: Detalhe da zona $M$ descontínua na interface de amanteigamento executado com o processo MIG.

A Tabela 7 evidencia a diferença entre os dois processos na quantidade e diversidade de ZPDs encontradas, onde a contagem de ZPD foi realizada fazendo uma busca ao longo de toda a interface de cada amostra, como auxílio do microscópio ótico. 
Tabela 7: Quantidade de ZPDs nas interfaces das amostras amanteigadas.

\begin{tabular}{l|l|l|l|l}
\hline \multirow{2}{*}{ AMOSTRA } & \multicolumn{4}{|c}{ FORMATO DA ZPD } \\
\cline { 2 - 5 } & Dedo & Ilha & Praia & Península \\
\hline A1-86P & 0 & 0 & 0 & 0 \\
\hline A2-86P & 0 & 0 & 0 & 0 \\
\hline B1-41P & 0 & 0 & 0 & 0 \\
\hline B2-41P & 0 & 0 & 0 & 1 \\
\hline B3-41P & 0 & 1 & 0 & 0 \\
\hline C1-86M & 18 & 3 & 2 & 0 \\
\hline C2-86M & 53 & 13 & 6 & 3 \\
\hline C3-86M & 34 & 4 & 4 & 3 \\
\hline D1-41M & 18 & 2 & 5 & 1 \\
\hline
\end{tabular}

O tipo de processo de soldagem e o nível de temperatura de preaquecimento utilizado exerceram uma influência considerável na extensão da zona $\Phi$. O efeito da temperatura de preaquecimento na extensão dessa zona pode ser observado através da Figura 11. Não necessariamente, as zonas descritas na Figura 8, têm que aparecer em toda a extensão da interface dissimilar. Isso dependo do nível das forças convectivas na poça de fusão e da formação de uma zona estagnada e de escoamento laminar, como explicam Kou e Yang, citados por OLIVEIRA [19]. Além disso, na região de interpasse, a interface apresenta características diferentes de uma região central do cordão, sendo que a Zona $\mathrm{M}$ se forma principalmente na região de interpasse [1].

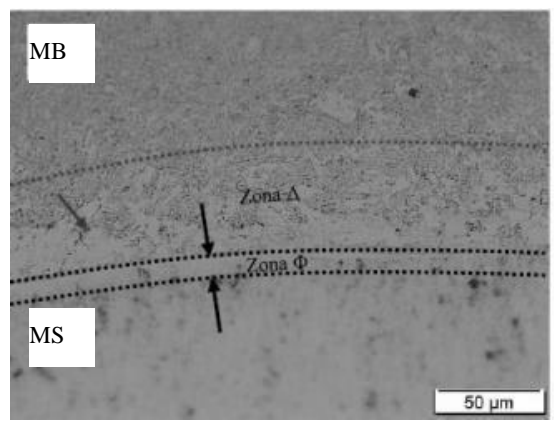

(a)

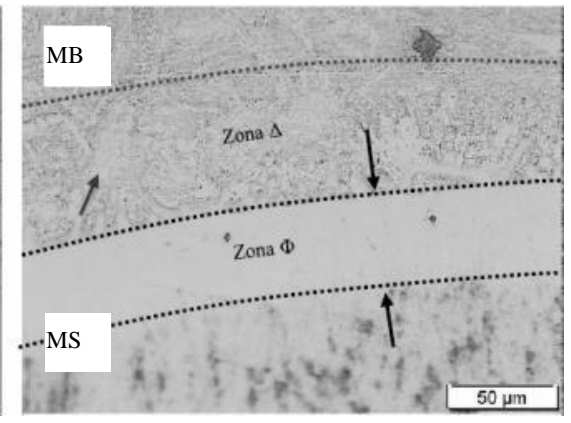

(b)

Figura 11: Influência do preaquecimento sobre a extensão da zona $\Phi$. a) Amostra C1-86M, com preaquecimento de $200^{\circ} \mathrm{C}$ e interpasse de $240^{\circ} \mathrm{C}, 500 \mathrm{x}$. b) Amostra C3-86M, com preaquecimento de $280^{\circ} \mathrm{C}$ e interpasse de $370^{\circ} \mathrm{C}, 500 \mathrm{x}$.

A Tabela 8 apresenta os resultados quantitativos de extensão para a zona $\Phi$ em todas as amostras, reforçando o que é mostrado na Figura 11.

Tabela 8: Valores médios (10 medidas) das extensões da zona $\Phi$

\begin{tabular}{l|l|l}
\hline \multicolumn{3}{c}{ EXTENSÁO DA ZONA $\Phi(\boldsymbol{\mu m})$} \\
\hline AMOSTRA & MÉDIA & DESVIO PADRÃO \\
\hline A1-86P & 4,78 & 079 \\
\hline A2-86P & 6,30 & 1,30 \\
\hline B1-41P & 11,50 & 1,20 \\
\hline B2-41P & 20,50 & 0,90 \\
\hline B3-41P & 22,80 & 1,70 \\
\hline C1-86M & 29,60 & 1,90 \\
\hline C2-86M & 33,20 & 1,60 \\
\hline C3-86M & 58,70 & 2,20 \\
\hline
\end{tabular}

O efeito do aumento da temperatura de preaquecimento sobre a extensão da ZPD e, consequentemente, sobre o gradiente de composição química ao longo da sua extensão pode ser observado através das Figuras 12 e 13. 


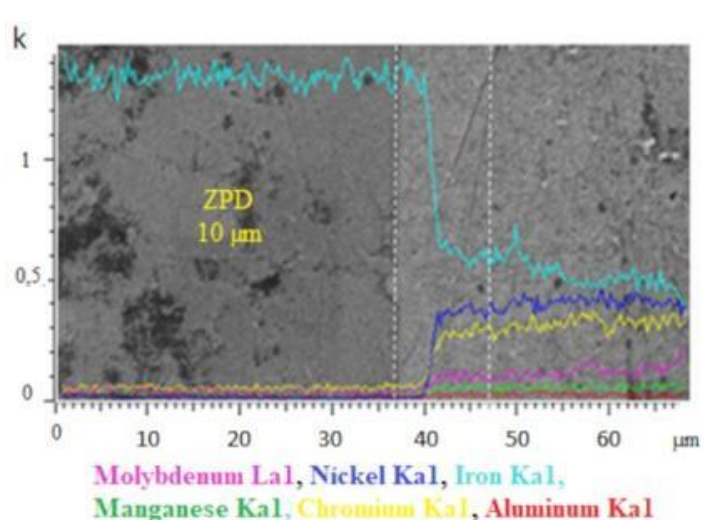

(a)

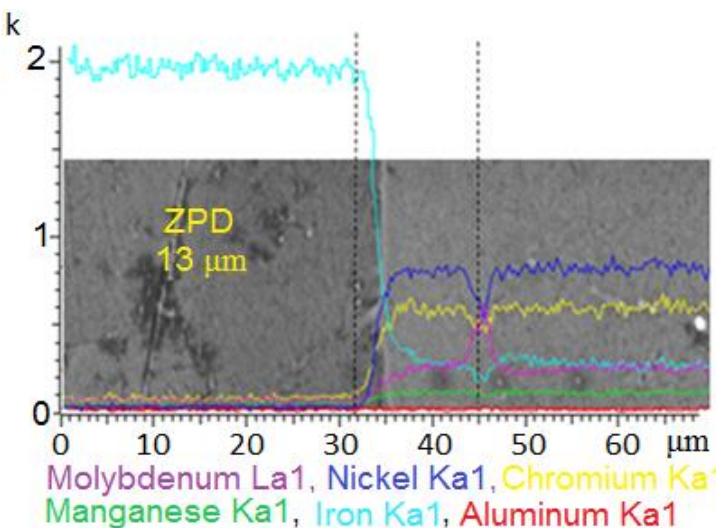

(b)

Figura 12: Perfil de composição química ao longo da ZPD das amostras B1-41P (a) e B3-41P (b).

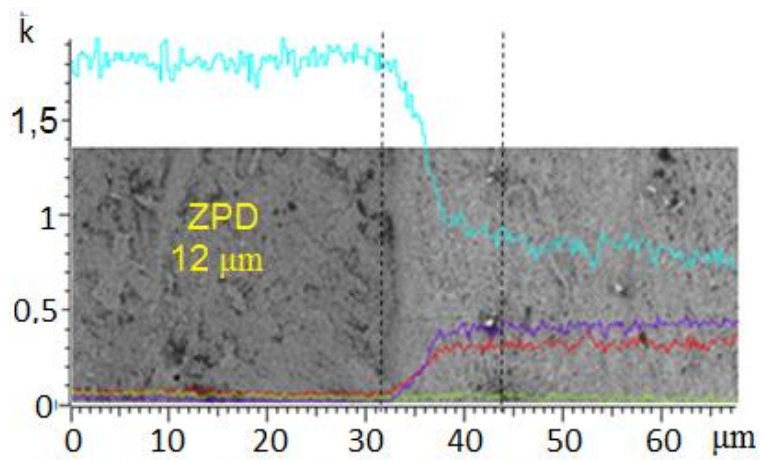

Nickel Ka1, Iron Ka1, Manganese Ka1, Chromium Ka1

(a)

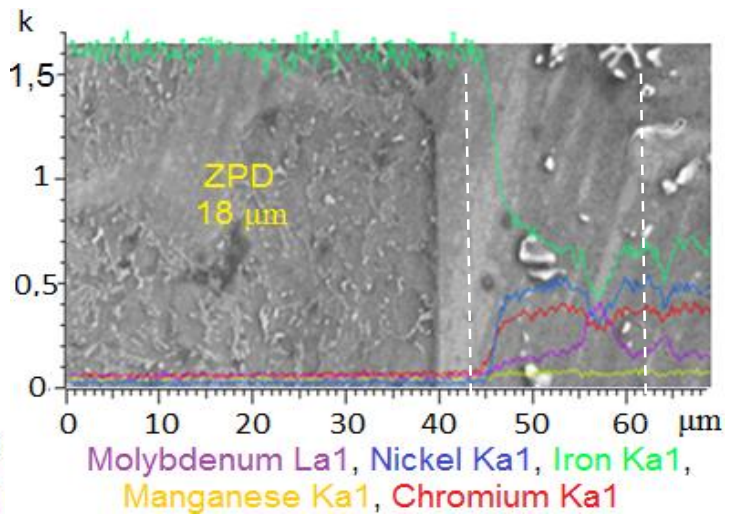

(b)

Figura 13: Perfil de composição química ao longo da ZPD das amostras C1-86M (a) e C3-86M (b).

Vale ressaltar que essa faixa de composição química intermediária - a qual é classificada como uma ZPD contínua - foi aqui delimitada e teve sua extensão estimada, considerando-a como uma faixa onde se teve variações bruscas de composição química, principalmente os teores de $\mathrm{Fe}, \mathrm{Cr}$ e Ni. Sendo o primeiro o elemento predominante no aço e os outros dois elementos predominantes na liga de níquel. Nota-se que para maiores temperaturas de preaquecimento, além do aumento da extensão da ZPD, ocorre também uma maior heterogeneidade da composição química. Sendo que, a heterogeneidade ficou mais evidente na Figura 12.

A variação das temperaturas de preaquecimento e interpasse, também provocaram diferenças nos níveis de migração de Fe do substrato (aço) em direção ao amanteigamento. A análise química pontual mostrou que para as amostras A1-86P e A2-86P, por exemplo, os valores de teor de Fe no fim da zona $\Phi$ foram respectivamente $11,06 \%$ e $16,94 \%$. E no meio da zona $\Phi$ foram respectivamente de $39,26 \%$ e $59,11 \%$, apresentando assim uma tendência de aumento do teor de ferro na região da zona $\Phi$, com o aumento das temperaturas de preaquecimento e interpasse, de acordo com o que era esperado. O restante das amostras se comportou da mesma forma, apresentando essa mesma tendência.

A Figura 14 ilustra o efeito do TTAT na interface de uma amostra amanteigadas com PTA-P, evidenciando o aumento da extensão da zona $\Delta$ com o a aplicação do TTAT. 


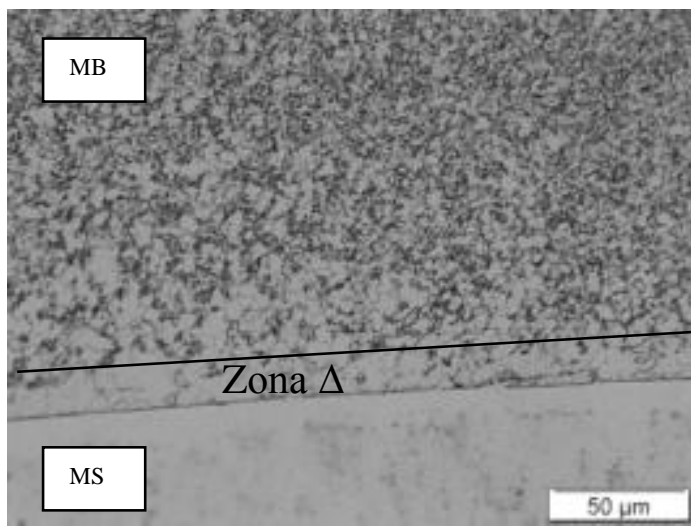

(a)

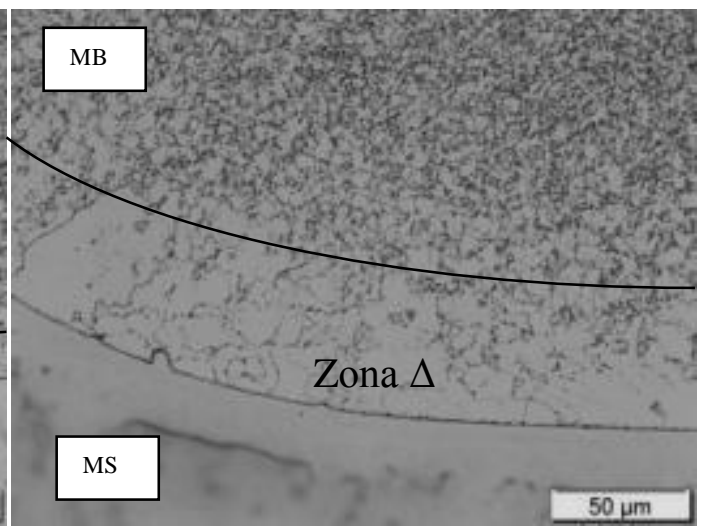

(b)

Figura 14: Interface de amostras amanteigadas com o processo PTA-P antes do TTAT (a) e depois do TTAT (b).

Para avaliar o efeito do processo de soldagem e do TTAT sobre a variação da composição química do amanteigamento a partir da linha de fusão, foram realizadas análises químicas pontuais, por EDS, nas regiões indicadas na Figura 15 como MS1, MS2 e MS3. Os pontos coincidem com a localização da zona $\phi$.

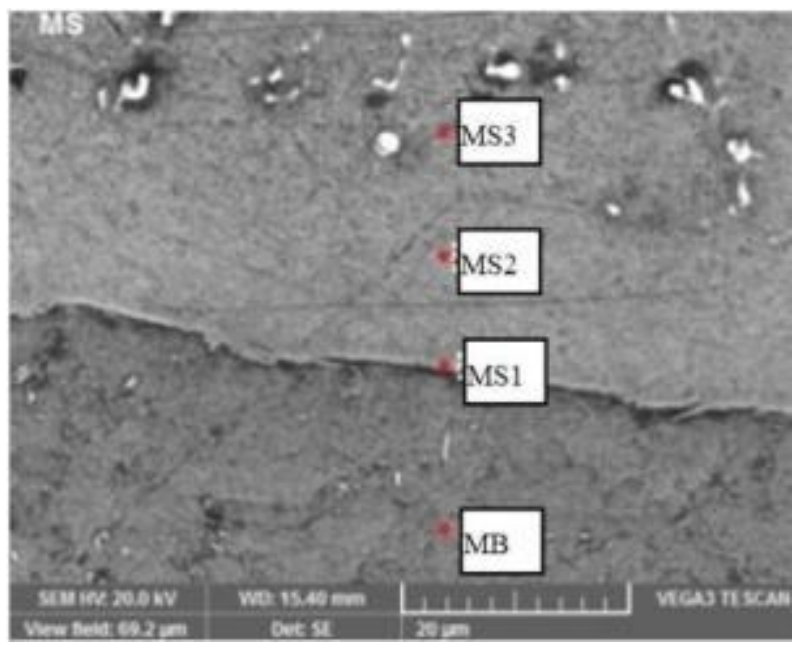

Figura 15: Regiões onde foram realizadas análises químicas por EDS.

A Figura 16 apresenta os valores pontuais dos elementos químicos para amostras A1-86P e C1-86M.

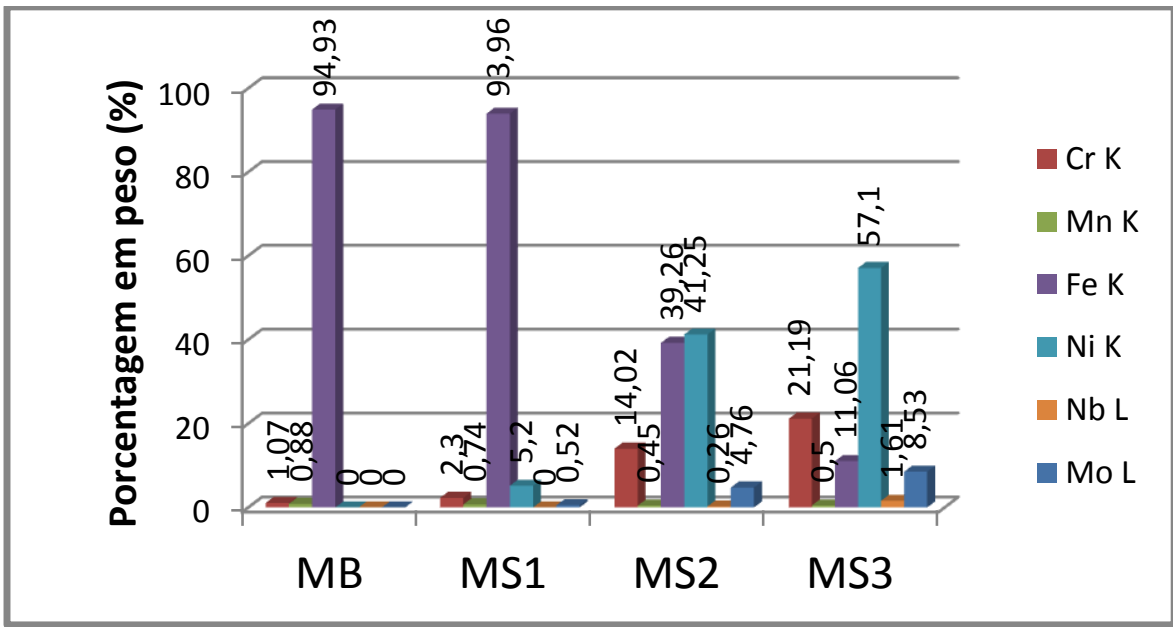

(a) 


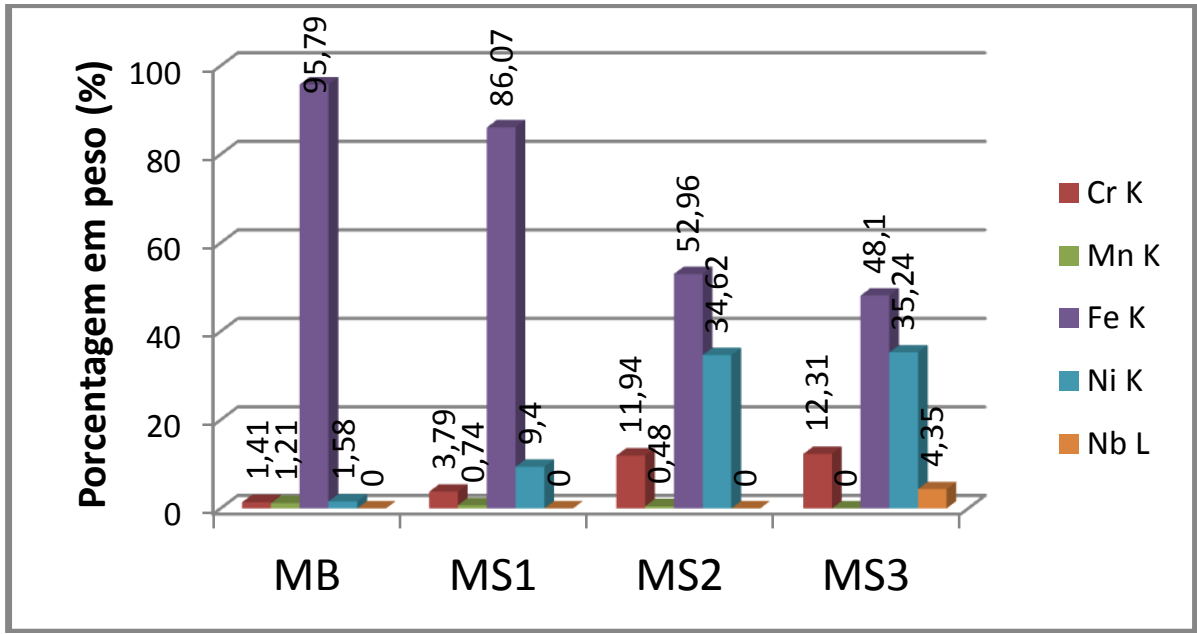

(b)

Figura 16: Composições químicas em pontos da ZPD utilizando o processo PTA-P (amostra A1-86P) (a) e o processo MIG (amostra C1-86M) (b).

Observa-se que os amanteigamentos feitos pelo processo PTA-P (A1-86P) apresentaram menores teores de $\mathrm{Fe}$ e maiores teores de $\mathrm{Ni}, \mathrm{Cr}$ e $\mathrm{Mo}$ nos pontos MS2 e MS3 em relação aos amanteigamentos realizados pelo processo MIG (C1-86M e D1-41M). Isto ocorreu de forma similar para as outras amostras.

A Tabela 9 apresenta os valores médios de microdureza em cada amostra nas regiões correspondentes ao amanteigamento (MS) e à zona termicamente afetada (ZTA). A letra T no final da nomenclatura de algumas amostras significa que as mesmas foram submetidas ao TTAT.

Percebe-se que antes do TTAT a maioria dos valores médios na ZTA foram superiores a $300 \mathrm{HV}$, acima do limite de $250 \mathrm{HV}$ estabelecido pela NACE MR 0175 [20]. Entretanto, após a aplicação do TTAT, estes valores reduziram significativamente, principalmente nas amostras em que se utilizou o aço AISI $8630 \mathrm{M}$, demonstrando assim, a necessidade deste tratamento.

Tabela 9: Valores médios de microdureza no amanteigamento (MS) e na ZTA

\begin{tabular}{l|l|l|l|l}
\hline \multicolumn{1}{c|}{ AMOSTRA } & $\begin{array}{l}\text { MÉDIA MS } \\
(\mathbf{H V})\end{array}$ & $\begin{array}{l}\text { DESV. PAD. } \\
\text { MS (HV) }\end{array}$ & $\begin{array}{l}\text { MÉDIA ZTA } \\
(\mathbf{H V})\end{array}$ & $\begin{array}{l}\text { DESV. PAD. } \\
\text { ZTA (HV) }\end{array}$ \\
\hline A1-86P & 272,8 & 37,8 & 308,2 & 51,4 \\
\hline A2-86P & 274,0 & 52,3 & 348,5 & 35,7 \\
\hline B1-41P & 235,5 & 15,0 & 242,3 & 17,8 \\
\hline B2-41P & 219,9 & 18,9 & 247,9 & 17,2 \\
\hline B3-41P & 226,9 & 15,0 & 249,5 & 9,8 \\
\hline C1-86M & 258,9 & 43,4 & 308,6 & 32,4 \\
\hline C2-86M & 241,5 & 50,0 & 322,3 & 63,1 \\
\hline C3-86M & 254,2 & 50,0 & 361,8 & 46,2 \\
\hline A1-86P-T & 241,4 & 15,9 & 205,4 & 17,5 \\
\hline A2-86P-T & 219,8 & 10,8 & 219,6 & 15,5 \\
\hline B1-41P-T & 226,8 & 17,0 & 189,1 & 13,0 \\
\hline B2-41P-T & 224,4 & 16,8 & 198,1 & 9,5 \\
\hline B3-41P-T & 228,7 & 9,3 & 198,2 & 13,9 \\
\hline C1-86M-T & 224,7 & 14,0 & 191,1 & 16,0 \\
\hline C2-86M-T & 230,4 & 15,7 & 207,2 & 19,9 \\
\hline C3-86M-T & 219,7 & 11,9 & 228,7 & 18,5 \\
\hline
\end{tabular}

Os resultados mostram que a aplicação do TTAT homogeneizou os valores de dureza, o que pode ser visto através da diminuição dos valores de desvio padrão.

A influência do TTAT e do tipo de aço na ZTA fica mais evidente ao se observar o gráfico da Figura 17 que mostra a diminuição dos valores de microdureza em todas as amostras depois do TTAT. 


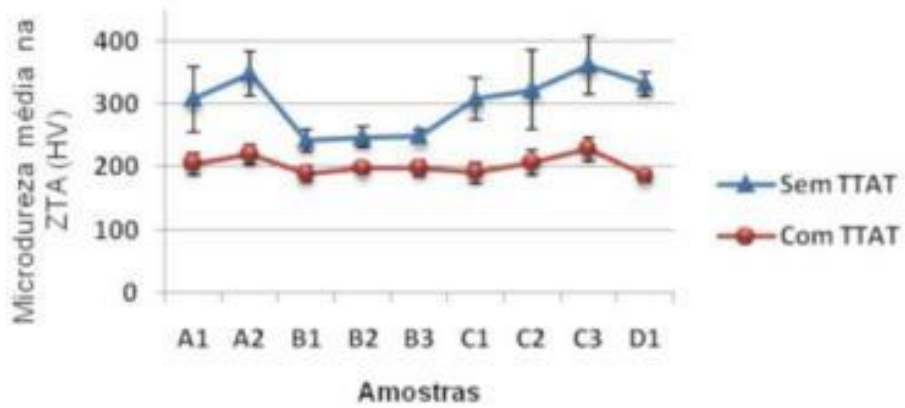

Figura 17: Efeito do TTAT sobre os valores de microdureza na ZTA.

Com relação ao efeito do preaquecimento, pode-se observar que o aumento do seu valor proporcionou um acréscimo nos valores de microdureza na ZTA, principalmente das amostras em que se utilizou o aço AISI $8630 \mathrm{M}$. O aumento de temperatura pode ter favorecido a precipitação de partículas duras que teriam o efeito de ancoragem dos grãos e consequentemente o seu refino.

Os valores de microdureza ao longo da interface, no sentido horizontal, comprovaram os altos valores para as ZPDs, atingindo valores de até $649 \mathrm{HV}$ nas amostras com o aço AISI 8630M utilizando o processo MIG, conforme ilustrado na Figura 18. As amostras com o mesmo aço utilizando o processo PTA-P e as amostras utilizando o aço AISI 4130 indicaram menores valores de microdureza, conforme ilustrado na mesma figura. Essa diferença de microdureza entre os dois processos pode está associada à diferença nas velocidades de soldagem utilizadas em cada processo, como será explicado na discussão dos resultados.

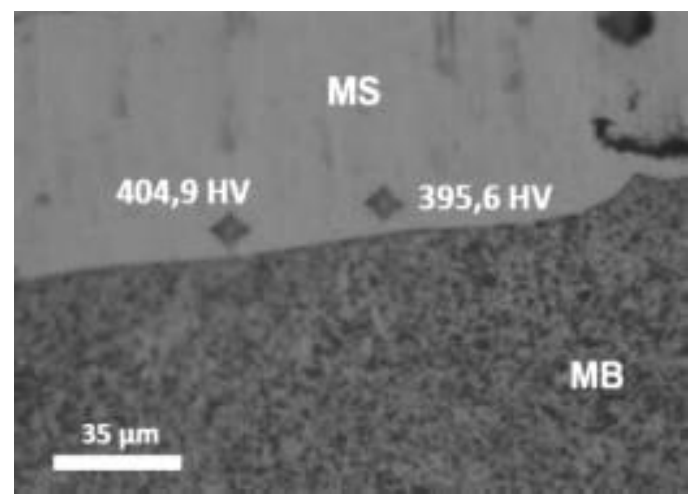

(a)

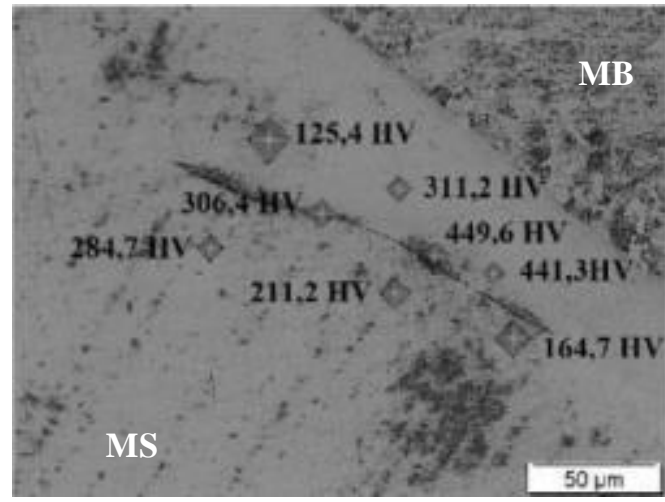

(c)

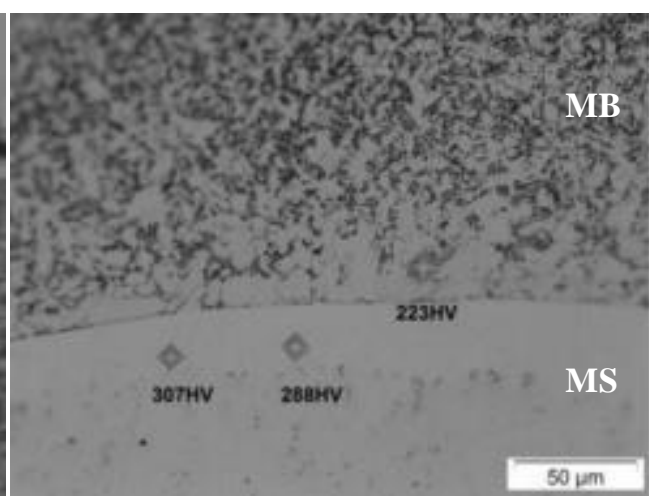

(b)

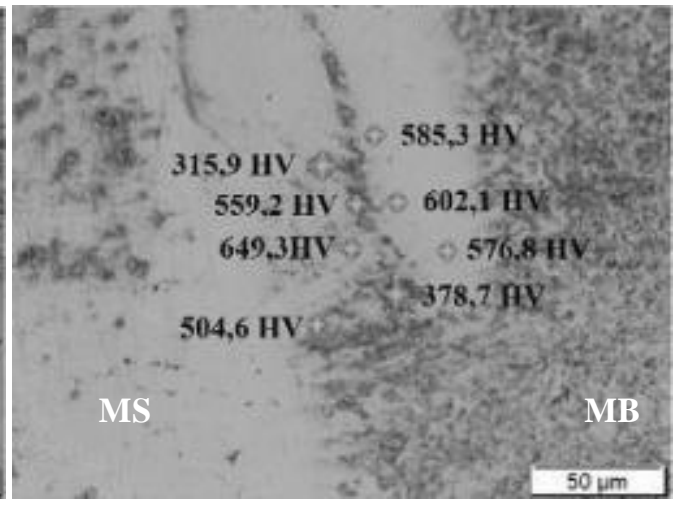

(d)

Figura 18: Valores de microdureza ao longo da interface. a) A1-86P, b) B3-41P, c) C1-86M. d) C3-86M.

\section{DISCUSSÃO}

Comparando as seções transversais dos amanteigamentos feitos com PTA-P e os feitos com MIG, mostradas nas Figuras de 3 a 5, percebe-se que, de uma forma geral o processo PTA-P fornece um aspecto mais uniforme, com menores quantidades de picos de penetração do MS no MB, resultando em áreas de 
penetração menores. Além disso, o processo MIG resultou em valores de diluição significativamente superiores aos valores alcançados através do processo PTA-P, como pode ser observado na Tabela 6. A maior diluição no processo MIG pode ser atribuída à maior quantidade de picos de penetração. Essa maior quantidade de picos talvez pudesse ser diminuída utilizando outro ângulo de ataque, diferente de $90^{\circ}$ com a superfície da chapa. Porém, utilizando o mesmo ângulo, o processo PTA-P resultou em menores quantidades de picos de penetração e menor diluição global.

A penetração da solda depende, entre outros fatores, da pressão que o fluxo de plasma exerce na poça de fusão. O que pode se afirmar aqui é que a combinação de variáveis resultou nessa baixa penetração para os amanteigamentos com PTA-P. Por exemplo, ao diminuir o diâmetro do bico constritor, essa pressão aumentaria e resultaria em maior penetração. Devido à grande quantidade de variáveis envolvidas nos processos, é muito complexa a comparação entre resultados de diferentes processos e deve ser feita com muita cautela. Mas de forma geral, sabe-se que no processo PTA-P resulta em menores diluições que no GMAW.

Comparando as amostras com diferentes temperaturas de preaquecimento e interpasse, nota-se que este parâmetro influenciou de forma significativa nos valores de diluição global dos amanteigamento, como pode ser visto na Tabela 6. Para maiores temperaturas de preaquecimento e interpasse, nota-se uma tendência de aumento dos valores de diluição. Esse comportamento já era esperado, pois com maiores temperaturas iniciais da chapa, a interface MB/MS apresenta taxa de solidificação mais lenta, favorecendo a mistura entre as ligas metálicas.

As interfaces entre os aços AISI 8630M e 4130 e as camadas de amanteigamento com Inconel 625 se apresentaram com características microestruturais mais uniformes, quando executadas com o processo PTA$\mathrm{P}$, quando comparada com as interfaces executadas com o processo MIG, conforme pode ser observado nas Figuras 6 e 7. Estas penetrações denominadas de dedos ocorreram com maior frequência nas interfaces das soldas realizadas com o processo MIG e são formadas através da liquação dos contornos de grão do metal de base mais próximo à linha de fusão. As forças convectivas na poça de fusão ajudam o metal de solda a penetrar entre esses contornos fundidos do aço. A maior corrente de soldagem para o processo MIG pode ter causado movimentos hidrodinâmicos mais intensos, contribuindo para essas formações. A composição química desses dedos é bem semelhante à composição da região do metal de solda mais próximo e contem um elevado teor de Fe [1, 19]. Outros autores também identificaram essas estruturas em suas caracterizações, como Beltrão ao observar a interface dissimilar do aço AISI 4130 amanteigado com liga de níquel Inconel 625 no MIG convencional e Dodge ao estudar a interface de soldas dissimilares entre aço AISI 8630 e liga de níquel Inconel 625 [6, 21]. Nesses estudos não foram encontradas correlações dessas estruturas com as propriedades mecânicas do revestimento.

A Figura 8 ilustra diferentes zonas que podem fazer parte de uma ZPD. Do lado do aço (parte inferior da Figura 8) existe uma zona descarbonetada denominada $\Delta$, caracterizada por uma faixa onde se predomina grãos de ferrita, e ao lado, uma zona $\mathrm{M}$, martensítica. Do lado da liga de Ni, uma zona $\Phi$, austenítica, supersaturada de $\mathrm{C}$ e de crescimento planar, seguida de uma zona $\pi$, austenítica com estrutura dendrítica, com partículas (carbonetos) entre estas dendritas. As zonas M e $\Phi$ têm elevada dureza, sugerindo uma condição de baixa tenacidade, logo, podem ocasionar fragilização na presença do hidrogênio. A zona M é um tipo de ZPD descontínua e pode está presente junto com diferentes ZPDs de diferentes formatos, que por ter semelhança com alguns acidentes geográficos naturais, são denominadas de ilhas, praias penínsulas, etc [3, 22].

As Figuras 9 e 10 mostram exemplos de ZPDs encontradas nas interfaces dos amanteigamentos executados com MIG, com a frequência indicada na Tabela 7. Comparando as amostras amanteigadas com o processo PTA-P com aquelas amanteigadas pelo processo MIG, foi notável a maior quantidade de ZPD, inclusive da zona $\mathrm{M}$ na interface das amostras amanteigadas com o processo MIG. Resultado que pode ser atribuído à menor diluição global para o PTA-P. A literatura mostra que maior diluição global resulta em maior quantidade de ZPDs em soldagem dissimilar [9]. Foram encontradas muito poucas ZPDs do tipo descontínua nos amanteigamentos realizados pelo processo PTA-P, apenas as zonas $\Phi$ e zonas $\Delta$, que se estendem por grande parte da interface em todos os amanteigamentos. A baixa frequência com que se apresentam essas ZPDs descontínuas nos amanteigamentos feitos pelo processo PTA-P implica em menores riscos de trincamento pelo hidrogênio. Beaugrand apud Beltrão, explica que a presença dessas zonas $\Phi$ e zonas $\Delta$ tem influência em mecanismos de fratura, sua composição varia de acordo com o processo de soldagem e com a realização de tratamento térmico de alívio de tensões. [6]

A quantidade relativamente grande de ZPD encontrada com o MIG pode está associada com uma excessiva velocidade de soldagem para a corrente utilizada. Essa hipótese é baseada na deficiência dos movimentos hidrodinâmicos, responsáveis pela mistura e homogeneização do metal solda, quando há uma 
atuação do arco durante um rápido intervalo de tempo, o que causa uma rápida solidificação, contribuindo para a formação de ZPD [9].

A diluição e o nível de preaquecimento utilizado exerceram uma influência considerável na extensão da zona $\Phi$, o que pode ser observado através da Figura 11, Tabela 6 e Tabela 8. O processo MIG apresentou zonas $\Phi$ mais extensas, provavelmente, por apresentar maiores níveis de diluição, como pode ser visto na Tabela 6. Ficou evidente que, com o aumento da temperatura de preaquecimento, esta extensão (zona $\Phi$ ) indicada pelas setas se tornou maior do que nas amostras com menor temperatura de preaquecimento. Segundo a bibliografia, altas temperaturas de preaquecimento, bem como menores velocidades de soldagem resultam na formação de uma faixa mais espessa da zona $\Phi$ na interface, devido ao decréscimo na taxa de solidificação [9]. Como a poça de fusão demorará mais para solidificar, ficando o metal fundido por mais tempo, as forças convectivas conseguem atuar por mais tempo, provocando supostamente uma maior mistura na interface do amanteigamento, assim como maiores níveis de migração de elementos químicos. A Tabela 8 apresenta os valores médios das extensões da zona $\Phi$ nas amostras amanteigadas. Percebe-se que as amostras amanteigadas com o processo MIG e com maiores valores de preaquecimento apresentaram maiores extensões. Dodge et al. apud Roneles Silva afirmam que a presença dessa zona planar $\Phi$ pode ter influência na nucleação de defeitos. Segundo suas observações, trincas se propagaram nessa zona, o que pode tornar a junta soldada mais susceptível à fragilização por hidrogênio. [22].

Durante o TTAT a manutenção da peça a $676^{\circ} \mathrm{C}$ por 2 horas fez com que o carbono sofresse uma maior migração, empobrecendo ainda mais essa região de carbono e favorecendo a formação da ferrita na zona descarbonetada (zona $\Delta$ ) e a formação de carbonetos na região interdendrítica da zona $\pi$. Logo, foi constatado que o tratamento térmico para alívio de tensões influenciou significativamente no aumento da extensão dessas zonas descarbonetadas. Antes do TTAT as extensões dessas zonas eram em torno de no máximo $50 \mu \mathrm{m}$ nos locais onde foram detectadas. E depois do TTAT essas extensões passaram a ser de 50 $\mu \mathrm{m}$ a $250 \mu \mathrm{m}$, com um crescimento muito evidente para as amostras do grupo C, AISI 8630M amanteigadas pelo processo MIG.

Os resultados de análise química pontual nas interfaces dos amanteigamentos evidenciaram que a diluição local (na região da zona $\Phi$ ) para os amanteigamentos feitos pelo processo MIG foram maiores, o que pode ter sido resultado da grande diferença entre os valores de corrente de soldagem para cada processo, 195A para o PTA-P contra 260A para o MIG.

Os resultados de microdureza (Tabela 9 e Figura 17) mostraram que a aplicação do TTAT foi importante para a redução dos valores de dureza da ZTA. Resultados semelhantes foram observados em outros trabalhos [12, 23]. Pode-se observar também que os valores de desvio padrão foram notavelmente menores depois da realização do TTAT, mostrando que esse tratamento térmico não só diminuiu a dureza, como homogeneizou o seu valor nas regiões estudadas. O TTAT foi de fundamental importância para a redução da microdureza na região de interface analisada. Rodrigues, Maciel e Cruz Neto em sua pesquisa sobre amanteigamento de aço AISI 8630m com a liga AWS ER 80S-D2 também concluíram que o TTAT teve como resultado a redução da microdureza na região de interface [24]. Porém existem evidências de que o TTAT pode resultar em aumento de dureza em determinadas regiões, dependendo da combinação entre o metal de base e metal de solda, do processo e das variáveis de soldagem. Anne Martins constatou aumentos de dureza na Zona $\phi$ de amostras submetidas ao TTAT, o que foi atribuído à difusão de carbono durante o TTAT. Porém, na ZTA, foi possível a redução da microdureza. [25]

A elevação das temperaturas de preaquecimento e interpasse pode ter causado um maior favorecimento para a precipitação de carbonetos, elevando a dureza da ZTA. Principalmente no aço AISI 8630M, por ter um maior teor de C e de Mo. Esse fenômeno de precipitação de carbonetos foi constatado também por Oliveira [19]. Neste caso, o refinamento do grão na região teria a contribuição do ancoramento do mesmo pelos carbonetos precipitados. Em outros aços o preaquecimento pode ter efeitos contrários. Fernando da Silva, estudando a interface de soldas entre aço de baixo carbono com o aço AISI 4130, constatou que o aumento da temperatura de preaquecimento de $150{ }^{\circ} \mathrm{C}$ para $400^{\circ} \mathrm{C}$ resultou em uma diminuição dos valores de microdureza de até $71 \mathrm{HV}_{0,1}$. Tal efeito foi atribuído a transformação da martensita em ferrita de segunda fase não alinhada, porém houve uma queda de $71 \%$ na tenacidade medida pelo ensaio de impacto Charpy [26].

Os maiores valores de microdureza encontrados na interface MS/MB, assim como, a maior quantidade de ZPD encontrada para o processo MIG, podem estar associados a uma velocidade de soldagem mais elevada utilizada nesse processo. A atuação do arco durante um rápido intervalo de tempo, associado à rápida solidificação, dificulta os movimentos hidrodinâmicos responsáveis pela mistura e homogeneização do metal solda, resultando assim na formação de discretas ZPDs [9]. 


\section{CONCLUSÕES}

Diante dos resultados apresentados, destacam-se as seguintes conclusões:

-Os amanteigamentos executados com o processo PTA-P apresentaram uma interface mais homogênea, com menores áreas de penetrações e menor diluição, quando comparada com aquelas executadas com o processo MIG. Nesse aspecto o PTA-P apresenta a vantagem de gerar um revestimento com composição química mais favorável.

-A presença das ZPDs na interface proporcionou valores elevados de microdureza, alcançando até 649 HV na interface do aços AISI 8630M amanteigados com o processo MIG. Valores elevados de dureza são prejudiciais a tenacidade da junta, daí a necessidade de técnicas e processos que resultem em menor dureza.

-As interfaces dos amanteigamentos executados com o processo MIG apresentaram um maior número e diversidade de zonas parcialmente diluídas (ZPDs), quando comparadas com aquelas executadas utilizando o processo PTA-P. Sendo assim, com o PTA-P o risco de trincamento é menor.

-O aumento da temperatura de preaquecimento proporcionou um aumento da extensão da zona $\Phi$ e um aumento nos teores de Fe nesta região, elevando os valores de microdureza na interface, principalmente em amanteigamentos executados com o processo MIG. Esse é um ponto crítico, visto que o aumento da dureza pode acarretar em diminuição da tenacidade.

-A aplicação do tratamento térmico para alívio de tensões, além de homogeneizar a dureza dentro de cada região, proporcionou uma redução significativa nos valores de microdureza na interface, principalmente na interface dos amanteigamentos executados sobre o aço AISI 8630M. Logo, o TTAT é fundamental para garantir uma boa tenacidade da junta soldada.

\section{AGRADECIMENTOS}

À CAPES/CNPQ pela a ajuda financeira.

\section{REFERÊNCIAS}

[1] BEAUGRAND, V. C. M., SMITH, L. S., GITTOS, M. F., "Hydrogen Embrittlement of 8630M/625 Subsea Dissimilar Joints: Factors that Influence the Performance", In:ASME 2009 28th International Conference on Ocean, Offshore and Arctic Engineering. Honolulu, Hawaii, 2009a.

[2] BATISTA, V.R. Efeito do Processo de Soldagem e da Temperatura de Preaquecimento Sobre a Susceptibilidade à Fragilização por Hidrogênio de Juntas Soldadas Dissimilares Utilizadas no Setor Offshore da Indústria do Petróleo, Tese de D. Sc., Universidade Federal de Campina Grande, Campina Grande, Paraíba, Brasil, 2016.

[3] FENSKE, J. A., Microstructure and hydrogen induced failure mechanisms in iron-nickel weldments, Tese de D. Sc.,Universidade de Illinois, Urbana-Champaign, Illinois, EUA, 2010.

[4] SCHVARTZMAN, M. M. A. M., QUINAN, M. A. D., CAMPOS, W. R. C., LIMA, L. I. L., “Avaliação da Suscetibilidade à Corrosão sob Tensão da ZAC do aço inoxidável AISI 316L em Ambiente de Reator Nuclear PWR", Soldagem Inspeção, Vol. 14, n. 3, pp.228-237, São Paulo, Jul/Set 2009.

[5] CHRISTO, A., D’OLIVEIRA, A. S. C. M.,"Proteção de tubulações expostas ao coque”,In:VII Congresso Nacional de Engenharia Mecânica e Industrial,Curitiba - PR, 2007.

[6] BELTRÃO, D. M. Caracterização Microestrutura do Aço AISI 4130 Amanteigado com Ligas de Níquel., Dissertação de M.Sc., Programa de Pós-Graduação em Engenharia Mecânica, Universidade Federal da Paraíba, Campina Grande-PB, 2017.

[7] DODGE, M. F.; DONG, H. B.; GITTOS, M. F.; MOBBERLEY, T. "Fusion Zone Microstructure Associated With Embrittlement Of Subsea Dissimilar Joints", ASME 2014 34th International Conference on Ocean, Offshore and Arctic Engineering, San Francisco, California, USA., 2014.

[8] DAI, T.; LIPPOLD, J.C.;. "The effect of postweld heat treatment on hydrogen-assisted cracking of 8630/Alloy 625 overlay". Welding in the World, V.62, N³, pp. 581-599, 2018.

[9] KEJELIN, N. Z., Influência dos Parâmetros de Soldagem na Formação de Zonas Parcialmente Diluídas em Soldas de Metais Dissimilares, Dissertação de M.Sc. Universidade Federal de Santa Catarina, Florianópolis-SC, 2006.

[10] BRITO, F. F. G., Avaliação da Técnica de Dupla Camada na Soldagem TIG Considerando a Tenacidade e Características Metalúrgicas de Juntas de Aço AISI 8630M e ASTM A182 F22, Dissertação de M.Sc., Departamento de Engenharia Metalúrgica e de Materiais, UFC, Fortaleza-CE, 2014. 
[11] SILVA, C. C., AGUIAR, W. M., FARIAS, J. P.,"Técnica da Dupla Camada Aplicada no Reparo do Aço AISI 4340 sem TTPS - Efeito da Sobreposição de Ciclos Térmicos Sobre o Revenimento da ZAC", In: $63^{\circ}$ Congresso Anual da ABM, 2008, Santos-SP, 2008.

[12] DUARTE, S. M. A.,COSTA, E. C., ALMEIDA, J. G., CAVAlCANTE, F. J. N., LiMA, S. J. G. "Caracterização do Aço AISI 8630M Amanteigado com o Arame ER80S-D2 pelo Processo de Soldagem MAG”, In: Congresso Brasileiro de Engenharia de Fabricação, Salvador-BA, 2015.

[13] SANTOS, A. X., CAMPOS, A. R. N. ; MACIEL, THEOPHILO MOURA ; SANTANA, R. A. C. ; PRASAD, S. ; COSTA, J. D. ; SOUSA, M. B "Study on influence of the PTA-P welding process parameters on corrosion behavior of Inconel 625 coatings", Revista Matéria, v. 24, n.1, pp. 1-9, May, 2019.

[14] LUZ, T. S., COUTINHO, L., CANAL, A., "Study Parameters and Processes in Carbon Steel Coated Inconel 625 Using the Process PTA-P”, In: Rio Pipeline Conference \& Exposition, Rio de Janeiro-RJ, 2013.

[15] HINTON, B.Y. R. W., WISWESSER, R. K., "Estimating Welding Preheat Requirements for Unknown Grades of Carbon and Low-Alloy Steels", Welding Journal, v.87, pp. 273-278, Nov., 2008.

[16] American Association of State Highway and Transportation Officials (AASHTO)/AWS D1.5M/D1.5: 2008, Bridge Welding Code. C12.14 Preheat and interpass temperature control, p. 387, 2008.

[17] TAKANO, E. H., QUEIROZ, D., D'OLIVEIRA, A.S.C.M., "Evaluation of processing parameters on PTA hardfacing surfaces", Welding International, v. 24, pp. 241-248, 2010.

[18] NACE, International Standard MR0175/ISO15156,"Petroleum and Natural Gas Industries- Materials for use in $\mathrm{H}_{2} \mathrm{~S}$ - containing Environments in Oil and Gas Production, Part 2: Cracking-resistant carbon and low alloy steels, and the use of cast irons", 2003.

[19] OLIVEIRA, G. L. G., Soldagem Dissimilar dos Aços AISI 8630M e ASTM A182 F22 para Aplicações subaquáticas, Tese de D.Sc., Departamento de Engenharia Metalúrgica e de Materiais, UFC, Fortaleza-CE, 2013.

[20] NACE, International Standard MR0175/ISO15156,"Petroleum and Natural Gas Industries -Materials for use in $\mathrm{H}_{2} \mathrm{~S}$ - containing Environments in Oil and Gas Production, Part 1: General principles for selection of cracking-resistant materials", 2001.

[21] DODGE, M.F. The Effect of Heat Treatment on the Embrittlement of Dissimilar Welded Joints. Tese de D. Sc., University of Leicester, Leicester, Inglaterra, UK, 2014.

[22] SILVA, R. S., "Influência do hidrogênio na tenacidade a fratura quase estática de juntas dissimilares amanteigadas e soldadas com ligas de níquel". Tese de D. Sc., Departamento de Engenaria Mecânica. Universidade Federal da Paraíba, João Pessoa, Paraíba, Brasil, 2018.

[23] Costa, E. C., AlmeidA, J. G., DuARTe, S. M. A., CAVAlCANTE, F. J. N., Lima, S. J. G.,"Caracterização da ZTA do Aço SAE 8630, Decorrente do Amanteigamento Com o Inconel 625, com e sem Tratamento Térmico de Alívio de Tensões",In: Congresso Nacional de Engenharia Mecânica, Uberlândia-MG, 2014.

[24] RODRIGUES, L. C. X., Maciel, T. M., Cruz Neto, R. Q. "Avaliação da Microestrutura e do Perfil de Microdureza do Aço AISI 8630m Amanteigamento com Arame AWS ER 80S - D2". Revista Eletrônica de Materiais e Processos, v. 12, n. 2. pp. 124-131. ISSN 1809-8797. 2017.

[25] MARTINS, A. K. C. "Caracterização da interface da solda de amanteigamento do aço SAE $8630 \mathrm{M}$ com Inconel 725 pelo processo de soldagem MIG". Dissertação de M.Sc., Departamento de Engenharia Mecânica, UFPB, João Pessoa-PB, 2018.

[26] Silva, F. F. "Análise da influência das temperaturas de preaquecimento e TTPS na microestrutura e propriedades mecânicas da ZAC do aço AISI4130 soldado por SAW". Dissertação de M.Sc., Departamento de Engenharia de Materiais, Escola de Engenharia de Lorena, USP, São Paulo-SP, 2018.

\section{ORCID}

Valmir Rodrigues

Endira Maria Araújo Pereira

Ramon da Cunha Fonseca Fraga

Theophilo Moura Maciel
https://orcid.org/0000-0003-4434-641X

https://orcid.org/0000-0003-2432-1901

https://orcid.org/0000-0002-2607-2585

https://orcid.org/0000-0002-2539-3336 